\author{
MAITE GARBAYO MAEZTU \\ PROGRAMA DE BECAS POSDOCTORALES EN LA \\ UNIVERSIDAD NACIONAL AUTÓNOMA DE MÉXICO \\ MÉXICO
}

\title{
Dar presencia al cuerpo: prácticas performáticas en el tardofranquismo
}

\begin{abstract}
finales de la década de los años sesenta y principios de los setenta, en 4 un contexto artístico profundamente anquilosado tras casi 40 años 1 de dictadura franquista, surgieron toda una serie de prácticas experimentales que tienen en común el uso de nuevos medios y soportes y, en general, una actitud crítica hacia el panorama sociopolítico del momento.
\end{abstract}

El primer investigador que se ocupó de estas prácticas en el Estado espanool fue el crítico de arte Simón Marchán Fiz, quien las denominó los "nuevos comportamientos artísticos". En ellos, el performance o arte de acción ocupó un lugar relevante. El autor destacó el abandono progresivo de los medios tradicionales para recurrir a la fotografía, a las películas, documentos, proyectos, videos y, sobre todo, a "la renuncia al objeto permanente, la acentuación de lo efímero, el cultivo del proceso, la extensión del arte, la negación del valor de cambio". Insistió también en la importancia de la aparición de nuevos canales de distribución que ya no eran las galerías, sino más bien entidades sociales y culturales, institutos, colegios mayores universitarios y salas de cultura, que permitían el acceso a estas prácticas a un público diferente del tradicional.

A pesar de que Marchán Fiz publicó su libro en el momento álgido de los "nuevos comportamientos artísticos", lo que impedía la existencia de una reflexión retrospectiva y razonada de los mismos, el autor ya identificaba en ellos, como lo más decisivo, el afianzamiento progresivo de unas prácticas

I. Simón Marchán Fiz, Del arte objetual al arte de concepto (Madrid: Akal, I986 [1972]), 28I. 
artísticas enfrentadas a las dominantes, hecho que queda más claro aún si se atiende el desinterés con el que inicialmente fueron recibidas por la crítica, las galerías y el mainstream artístico del momento.

Juan Albarrán Diego se ha referido a la preponderancia en aquel momento de una concepción apolítica del arte, e identifica en los nuevos comportamientos una conexión con las luchas por las libertades de la oposición democrática:

llamaron la atención sobre problemáticas políticas muy concretas, recuperando los espacios públicos como ámbitos de protesta, restituyendo parte de la capacidad del artista como agente de transformación social y proponiendo la colectivización de la autoría así como la autogestión de la producción, difusión y exhibición de sus trabajos. ${ }^{2}$

Es indudable que la práctica artística no puede separarse del contexto sociopolítico que la alberga y, en este sentido, lo que Albarrán subraya es que los nuevos comportamientos representaron, al fin, una ruptura con la connivencia entre arte contemporáneo y Estado (franquista), que se perpetuaba ya durante bastante tiempo. El problema radica en que el relato de la historia del arte contemporáneo en España ha sido idéntico al sociopolítico: se marca un antes y un después entre la dictadura y la llegada de las libertades mediante la transición democrática. La cuestión es que esa transición, en lugar de rupturista, fue continuista, pactada y consensuada.

La escasa atención que en su momento se dedicó a las nuevas prácticas y la celeridad con la que cayeron en el olvido durante la transición hacen pensar en la importancia estético-política de las mismas, tesis que este artículo trata de sustentar, al poner el acento en el performance o arte de acción. Las nuevas prácticas fueron rupturistas en diversos aspectos. No sólo rompieron con la connivencia entre arte y Estado al quedar fuera del patrocinio estatal y buscar circuitos de presentación alternativos, sino que la utilización de nuevos medios, inédita hasta el momento en España, supuso una ruptura formal de enorme importancia. Las nuevas prácticas abrazaron la noción de proceso en detrimento del resultado final, pusieron en crisis la concepción objetualista y mercantilista del arte, así como el estatus de la figura del artista, e hicieron necesario pensar desde nuevos parámetros y posicionamientos estéticos.

2. Juan Albarrán Diego, "Del desarrollismo al entusiasmo: notas sobre el arte español en tiempos de transición”, Foro de Educación, núm. Io (2008): 170. 


\section{Performance}

Como ya se ha señalado, el performance, llamado entonces "arte de acción", ocupó un lugar destacable dentro de los nuevos comportamientos artísticos. En general, el análisis de estas prácticas resulta complejo, pues existen únicamente (y no en todos los casos) fotografías que documentan los performances. Imágenes que son simplemente un resto que da cuenta de una acción que no puede volver a reconstruirse ni a totalizarse. Pistas que es necesario complementar con una bibliografía aún escasa y con los testimonios orales de quienes las ejecutaron o estuvieron presentes en el momento de su realización.

El primer dato que estas imágenes arrojan es la presencia del cuerpo, su materialidad, su aparecer en un espacio y ante otros cuerpos. La forma en que lo corporal irrumpe en el campo de la visualidad y toma espacios físicos y simbólicos. Contemplar la documentación fotográfica de estas acciones hace que surjan diversas cuestiones: ¿¿cuáles son las implicaciones estético-políticas de la aparición de estos cuerpos justo en aquel momento y en aquel contexto? ¿Qué otros cuerpos estaban apareciendo, paralelamente, fuera del ámbito artístico, durante el tardofranquismo? ¿Cómo pensar la materialidad de los cuerpos dentro de la desmaterialización a la que tendían las prácticas artísticas del momento? ¿Cómo se materializan los cuerpos por medio del performance y la performatividad? ${ }^{3}$

Las imágenes y el relato oral dan cuenta ahora del paso del tiempo y del olvido en el que cayeron estas acciones durante la transición. El objetivo de este texto es citar, hacer aparecer estas acciones y estos cuerpos aquí y ahora, para que puedan ser repensados desde distintos posicionamientos críticos que contribuyan a cuestionar el relato de la historiografía del arte contemporáneo en el Estado español.

Uno de los problemas que se plantean es cómo hacer aparecer aquello que desde su construcción estaba amenazado por la desaparición. Se trata de prác-

3. La genealogía del término performativo hunde sus raíces en la teoría de los actos del habla propuesta por John Langshaw Austin en Cómo hacer cosas con palabras, trad. Genaro R. Carrió y Eduardo A. Rabossi (Barcelona: Paidós, 1982). Austin concibe los actos del habla como acciones con capacidad para incidir en la realidad. Posteriormente Jacques Derrida (197I) repensará el performativo austiniano al poner el acento en la citacionalidad, y Judith Butler (1990) hablará de actos corporales que mediante su repetición performativa terminan materializando cuerpos e identidades. La noción de performativo ha tenido una importante repercusión en el ámbito de las teorías y de las prácticas artísticas contemporáneas debido a que sitúa la noción de "acto" en el centro del discurso. 
ticas artísticas precarias, tanto por su carácter voluntariamente efímero, como por el hecho de que sucedían (en un principio, al menos) alejadas de los circuitos oficiales. Pero también son una serie de acciones que se producen en un espacio dictatorial, un espacio de censura, en el cual había muchas cosas que no se podían decir abiertamente. Si algo se aprendió en el franquismo fue a inventar estrategias para decir aquello que no se podía decir. La presencia del cuerpo, su puesta en escena mediante fragmentos y metonimias, hacía aparecer algunas cuestiones que no podían develarse de modo directo.

Los cuerpos que aparecen citan y hacen comparecer otros cuerpos: los que "desaparecieron" durante la guerra civil y la dictadura, los cuerpos enterrados en fosas anónimas y cunetas, los cuerpos femeninos coaccionados e invisibilizados por el nacional-catolicismo, los cuerpos perseguidos y castigados por no adecuarse a las normas de sexo-género. ${ }^{4}$

Como bien ha explicado Josefina Ludmer en su análisis de la "Respuesta a sor Filotea", existe una suerte de espacio baldío entre el lugar que uno se da y ocupa, frente al que le otorgan la institución y la palabra del otro. Un intersticio en el que se vuelve posible practicar o nombrar aquello que está vedado en otros espacios. Este ámbito comparece en las acciones que se analizan a continuación. Los cuerpos, por medio de hacerse presentes, ocupan un lugar dentro de la representación y se apropian de él.

Según la autora, de la separación entre el saber y el decir (en el que el saber es mi ley, y el decir, la ley del otro) pueden surgir otros modos de decir que se convierten en espacios de resistencia frente al poder de los otros. Ludmer señala que, para sor Juana, ese espacio es el silencio (no decir, pero saber) y añade que su movimiento "consiste en despojarse de la palabra pública: esa zona se

4. La ideología nacional-católica, por medio de la educación, la propaganda y la medicina, entre otros, estableció las bases de un modelo corporal al que los ciudadanos debían adaptarse. Eran dos modelos únicos: el masculino y el femenino, y todo aquello que escapase de esta lógica binaria o amenazase la totalización de sexo/género fue duramente perseguido por la ley. Ambos modelos estaban al servicio de los intereses de la patria (la feminidad entendida como abnegación y maternidad y la masculinidad como fuerza y virilidad para la defensa del régimen) y se definían por contraposición.

5. Texto escrito por sor Juana Inés de la Cruz en I69i como respuesta a las acusaciones que le hizo el obispo de Puebla, camuflado bajo el seudónimo de sor Filotea. El obispo no veía con buenos ojos que las mujeres se dedicasen a temas filosóficos. Véase Josefina Ludmer, "Tretas del débil”, en La sartén por el mango. Encuentro de escritoras latinoamericanas, eds. Patricia González y Eliana Ortega (Río Piedras: Ediciones Huracán, 1985). 
funde con el aparato disciplinario, y su no decir surge como disfraz de una práctica que aparece como prohibida". ${ }^{6}$

Este texto se ocupa de cuerpos que mediante el performance "dicen", que se sitúan en el lugar de la enunciación, en un momento y en un contexto en los que había muchas cosas que no se podían decir. El cuerpo, por medio de la materialidad y la gestualidad, se hace lengua. Se da una apropiación del lenguaje que lo tuerce y genera fisuras en su interior. Cambiar la palabra por el cuerpo conlleva una mediación estética, una pregunta sobre los modos hegemónicos de decir y un cuestionamiento sobre las formas de representar.

El complejo marco en el que se inserta la relación entre el saber y el decir es relevante a la hora de enfrentarse al análisis de estos performances. La negación, como señala Ludmer, se sitúa en medio del decir y del saber. El "no" es la censura, la prohibición, delimita aquello que no puede decirse ni nombrarse. Por eso frente al no, pueden inventarse estrategias, se puede torcer aquello que se dice, idear nuevas maneras de decirlo, transformar el discurso, alejarlo de la literalidad para que no pueda borrarse. Estas estrategias comparecen en muchas de las acciones de aquel periodo, y lo estético se convierte en un espacio de posibilidad. Por medio del cuerpo, del gesto, de esos espacios baldíos que se generan en la ejecución de la acción, demuestran que saben muchas formas de no decir: de decir sin decir. De este modo, cuestionan el lugar que ocupan algunos cuerpos dentro del campo del saber.

\section{Cuerpos que aparecen}

Los cuerpos de los que se ocupa este artículo no son los únicos que hacen su aparición en la arena pública estatal durante la década de los años setenta. Están los cuerpos del activismo, los del movimiento feminista que, inmediatamente después de la muerte de Franco, irrumpen en las calles con sus reivindicaciones y terminan por influir decisivamente en la agenda política de la transición. Estos cuerpos ocupan las calles, las plazas, se manifiestan, se encadenan a edificios gubernamentales y toman la noche ataviados con antorchas para reivindicar espacios de agencia. Los cuerpos feministas parten de la conciencia de su vulnerabilidad, pero en absoluto se doblegan ante ella. Por el contrario, tratan de redirigirla y la convierten en estrategia, pues

6. Judmer, "Tretas del débil", 3. 
por medio de ella reinventan las formas de hacer política para situar el cuerpo como eje central, como lugar en el que se materializa la afirmación "lo personal es político"?

Es importante que la aparición de los cuerpos no se dé únicamente en el dominio de lo artístico, aunque este hecho sea de vital importancia en lo que concierne a la puesta en crisis de la historia del arte, y a la proposición, desde lo estético, de nuevas formas de presentar y de mirar. El que por primera vez en Espańa un número significativo de mujeres accediera al ejercicio del arte tenía que ver con una sociedad que avanzaba y que cada vez era más permeable a otro tipo de presencias, como las constituidas por las activistas feministas que a partir de diciembre de 1975 comenzaron a aparecer en las calles. Ambas realidades se podrían leer de forma aislada, pero parece claro que su yuxtaposición en el tiempo no es mera coincidencia.

Hablo de cuerpos que "aparecen". Su irrupción desborda la visualidad del campo artístico del momento. Aunque cada puesta en escena de lo corporal pone en juego distintas cuestiones, la idea de hacerse presente es común a todas ellas. Uso el término "aparición" porque lo que se hace presente es aquello que no estaba previamente, o al menos no de esa forma. La presencia, como puede extraerse de las conceptualizaciones de Hans Ulrich Gumbrecht, compete en primera instancia a aquellas cosas que están en el mundo antes de que se les atribuya un significado, antes de que se vuelvan parte de una cultura. ${ }^{8}$ Cuando ciertas prácticas artísticas devienen acontecimiento, $y$ el cuerpo su elemento central, se pone en juego un tipo de presencia desconocida hasta entonces, y por tanto todavía no codificada en el nivel estético. Una presencia que hace gravitar estas propuestas artísticas entre su estatus de espectáculo y/o representación y su carnalidad autorreferencial. La separación entre sujeto y objeto, típica del arte tradicional, se problematiza, se altera, puesto que la corporalidad, la carnalidad, es anterior a toda interpretación que quien contempla pueda atribuir a lo que acontece. Como señala Erika Fischer-Lichte, esta alteración de la relación entre sujeto y objeto que se da

7. Lema que utilizó el movimiento feminista de la segunda ola, inspirado en el libro Sexual Politics (1970) de Kate Millet (Nueva York: Doubleday \& Company, Inc. 1970). La autora analiza las relaciones de poder que estructuran a la familia y la sexualidad para demostrar que aquello tradicionalmente circunscrito al ámbito de lo privado ha de ser considerado político, pues aquí se sustentan las estructuras de dominación que determinan el orden social.

8. Hans Ulrich Gumbrecht, Producción de presencia. Lo que el significado no puede transmitir, trad. Aldo Mazzucchelli (México: Universidad Iberoamericana, 2005). 
en el performance o arte de acción está estrechamente vinculada con la transformación de la relación entre materialidad y signicidad, entre significante y significado, pues la corporalidad o materialidad de la acción tienden a prevalecer sobre la signicidad. ${ }^{9}$ La obra de arte ya no es simplemente un objeto sobre el que un receptor (sujeto) proyecta significados e interpretaciones: en la acción, la dicotomía sujeto-objeto se trasciende a favor de una intersubjetividad: quienes están presentes en el acontecimiento se convierten en cierta forma en cosujetos del mismo, en un momento concreto, en un espacio concreto. Y ese espacio de tiempo en el que prevalecen la materialidad y la corporalidad (presencia de uno o varios cuerpos), posee en sí mismo un grado de independencia respecto a toda interpretación o dotación de significado que pueda producirse a posteriori.

Los actos corporales son fundamentalmente actos sociales, implican mi presencia en el otro y la presencia del otro en mí. Todo cuerpo y los actos que lo conforman están colonizados por sistemas de significación culturalmente naturalizados, por signos que se repiten hasta perder la referencia de un presunto original.

Si el cuerpo es la arena en la que se juega la subjetividad posmoderna, su presentación posee el potencial de alterar las estructuras de la historia y de la crítica del arte convencionales mediante la producción de un nuevo paradigma intersubjetivo en el que el sujeto se constituye siempre con relación a otro, y no ya como sujeto completo en sí mismo, sino más bien como sujeto en falta.

Cuando el cuerpo aparece, devela que no puede totalizarse ni universalizarse, que no puede fijarse en la representación. Por eso su sola presencia, concebida como presentación, posee el potencial de dislocar los discursos y las representaciones dominantes que habían tratado de fijarlo, de constreńirlo a un marco concreto desde el cual se gestaba un aparato ideológico de control. En el caso de España, en la época que me ocupa, la presentación del cuerpo está estrechamente ligada a un momento sociopolítico concreto marcado por un clima generalizado de insurrección, que en las prácticas artísticas se traduce en una apuesta por la experimentación que, como no podía ser de otra manera, parte de un cuestionamiento de la forma y de la adopción de nuevos lenguajes y nuevos medios.

9. Erika Fischer-Lichte, Estética de lo performativo, trad. Diana González Martín (Madrid: Abada Editores, 20II), 36. 


\section{Aparecerldesaparecer}

En la superficie de un muro blanco se recorta la silueta de una mujer, vestida de negro, las manos metidas en los bolsillos del abrigo. Dos fotografías documentan la secuencia de una acción, Herba (1973), llevada a cabo en la calle por Olga L. Pijoan (fig. I). Como si de dos fotogramas cinematográficos se tratase, las imágenes intentan captar el transcurso del tiempo y el movimiento de lo acontecido. La acción aborda la cuestión de la presencia a través de la fisicidad, de la materialidad del cuerpo. Un cuerpo que de pronto se esfuma, se desvanece, pero deja constancia de su presencia por medio de una silueta que se dibuja en el muro y queda como resto de la acción.

La aparición, aquí definida a partir de la desaparición, posee un componente fantasmático, fijado en las fotografías que documentan la acción. Al parecer, se trata de una intervención que no se realizó ante una audiencia, por lo cual se supone que la intención de Olga L. Pijoan fue construir la ficción de una desaparición mediante las imágenes resultantes, sin renunciar a concebir la pieza como acción.

Las dos fotografías documentan la presencia y la ausencia del cuerpo de la artista. La presencia se define en contraposición a la ausencia. La materia, el cuerpo, parecen cobrar existencia atendiendo a la evidencia de su falta, a partir de la cual, hablando en términos psicoanalíticos, ${ }^{\text {IO }}$ el sujeto construye su propia realidad. Si el fantasma es una manera de ser del sujeto frente al otro, de aparecer ante el otro, la realidad que el sujeto configura es siempre una fantasmatización de una supuesta realidad objetiva que se materializa a través del cuerpo.

En Herba, el cuerpo mismo aparece como en falta, destotalizado y desuniversalizado. La silueta, trazo de la desaparición, da cuenta de la incompletud inherente al cuerpo, de su fragmentación. La acción hace emerger un nuevo tipo de subjetividad que erosiona la concepción racionalista del sujeto monolítico, completo y entero, y propone como contrapartida un sujeto en falta, concentrado en un hacer-se constante. Un sujeto que sabe de su propia vulnerabilidad. El cuerpo, femenino en este caso, y el yo se juegan y se negocian por medio de la dialéctica entre ausencia/presencia, entre completud y falta. Si

IO. Para profundizar en la cuestión de la falta, véase: Jacques Lacan, "Ideas directivas para un congreso sobre la sexualidad femenina”, en Los escritos de Jacques Lacan, Escritos 2, Cinco (Barcelona: Paidós, 1995) y La relación de objeto, Seminario 4 (Barcelona y Buenos Aires: Paidós, 1995). 
DOI: http://dx.doi.org/10.22201/iie.18703062e.2016.108.2567

DAR PRESENCIA AL CUERPO
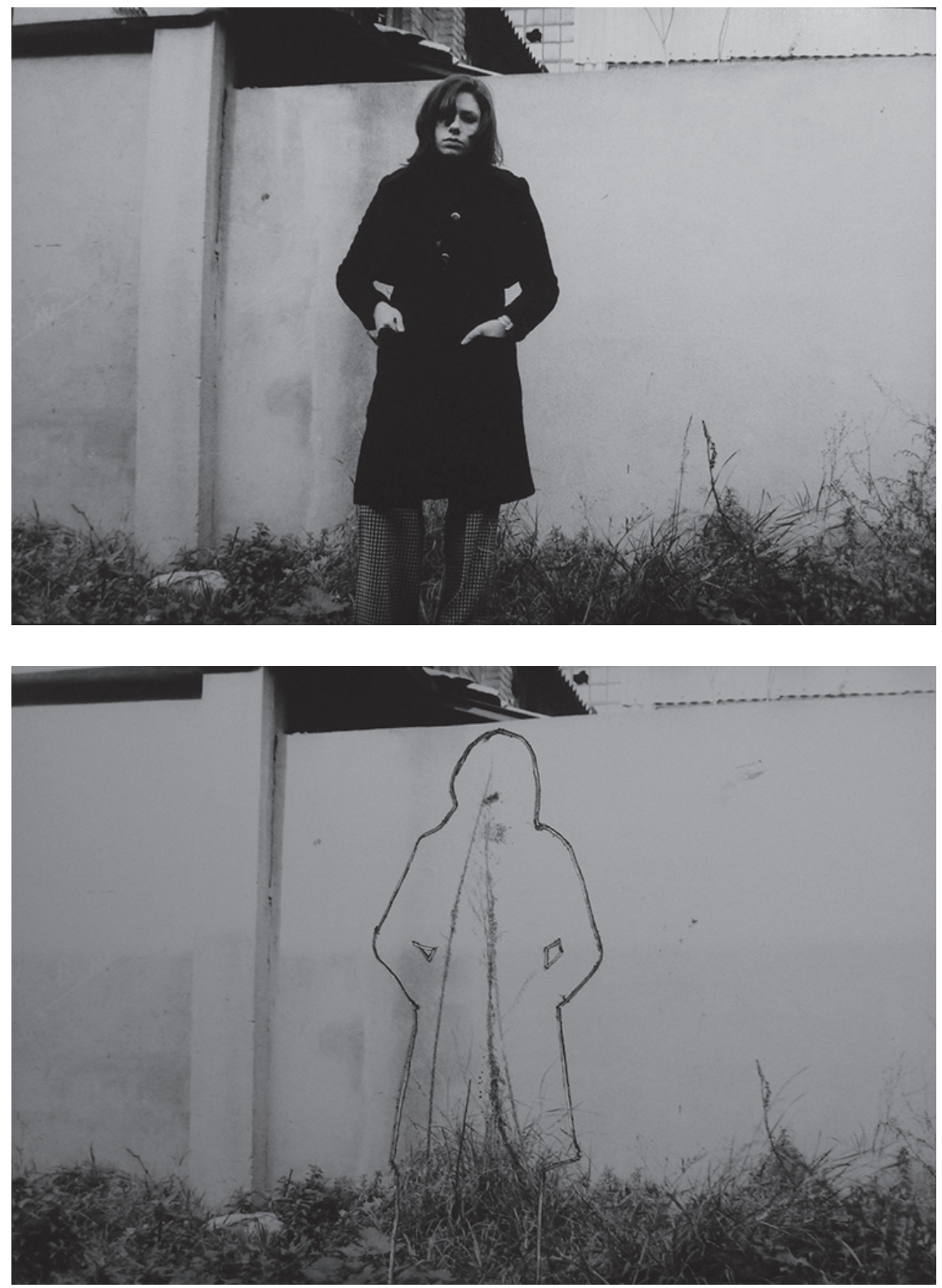

I. Olga L. Pijoan, Herba, I973, Barcelona. Archivos Pilar Parcerisas. 
la aparición implica una agencia, una toma de presencia en el espacio físico y simbólico, la desaparición da cuenta de la precariedad de esa misma toma, ya que sus efectos, al no depender únicamente del sujeto que la perpetra, están siempre sujetos a lo incalculable.

En Herba, el concepto de aparición adquiere nuevos sentidos: como contrapunto de la desaparición, por un lado, pero también en referencia al componente fantasmático que se desprende de las imágenes.

La aparición, abordada a profundidad por Martin Seel, ${ }^{\text {II }}$ está presente en toda actividad estética. En el performance, por su condición de acontecimiento, se genera un presente particular en el que la idea tradicional de representación no tiene cabida. En su lugar se impone la presentación: la aparición hace de la obra de arte, de la intervención, algo idéntico a sí mismo. Ya Adorno en su Teoría estética, al abordar la cuestión de la imagen, afirmaba que "en tanto que aparición y no en tanto que copia, las obras de arte son imágenes". ${ }^{\mathrm{I} 2} \mathrm{La}$ aparición funciona aquí como elemento de ruptura con la tradición mimética del arte, basada en una dinámica representacional. En su lugar, la imagen se concibe como presentación, como aparición, como aquello que no existía previamente y cobra existencia. Dice también Adorno que si la aparición es lo resplandeciente, lo que nos estremece, la imagen es el intento paradójico de conjugar esto fugacísimo. ${ }^{13}$ Lo fugaz, lo momentáneo, queda fijado de manera especial en la acción. Y la documentación, que toma la forma de imagen, sería ese intento de atrapar el instante. La relectura de Herba está mediada por su resto (las fotografías) como intento de conjugar la fugacidad del acontecimiento. Para Adorno, al definirse como aparición, "el arte lleva insertada teleológicamente su propia negación”. ${ }^{14}$ Lo que implica que el arte siempre deviene, se transforma o, como señalaría Adorno, es historia. Aunque en ningún momento él lo analiza en este sentido, parece claro que se introduce aquí, en el devenir, la noción de performatividad, de acto, de repetición: la aparición conlleva un hacerse en cada nueva aparición, un aparecer, cada vez, en formas diferentes, que terminaría por "negar" lo esencial de la aparición misma, de la acción misma, de la obra.

II. Martin Seel, Estética del aparecer, trad. Sebastián Pereira Restrepo (Buenos Aires y Madrid: Katz Editores, 20IO).

I2. Theodor W. Adorno, Teoría estética. Obra completa 7, trad. Jorge Navarro (Madrid: Akal, 2004), II7.

13. Adorno, Teoría estética. Obra completa 7, i18.

I4. Adorno, Teoría estética. Obra completa 7, i18. 
El aparecer me interesa sobre todo en cuanto compete a un cuerpo, cuestión que posee una especificidad muy concreta en el espacio de las prácticas performáticas. Aquello que no es necesariamente visible toma forma en el cuerpo, se encarna en él, aparece por medio de él.

En Herba, la ausencia/presencia es cuerpo, y a la vez el cuerpo queda definido a partir de esta oposición. El cuerpo siempre es performativo: por medio del acto, produce fuera de sí y se produce a sí mismo. El cuerpo, aquí, ha de verse como la encarnación de determinadas posibilidades históricas, que, en el análisis concreto de estas acciones, tienen que ver con la decadencia y con el final de la dictadura, y con los esfuerzos de los individuos y de los movimientos de resistencia antifranquista para materializar una apertura y una toma de presencia en el espacio público que implica siempre una toma de agencia.

El cuerpo de la esfera pública es masculino por excelencia. Su agencia es incuestionable y su identidad irreductible. El de la esfera privada es femenino e incompleto, sujeto siempre al devenir, y está despojado de agencia. Es, en cierto sentido, un cuerpo previo al sujeto político.

La imagen de Olga L. Pijoan, antes de desaparecer, afirma una presencia categórica. Se trata de un acto corporal que al hacerse público, al perpetrarse en un espacio social, y mediante el distanciamiento que deriva de su ímpetu estético, interviene en la cotidianeidad de ese mismo espacio y produce una transformación cuyos efectos son difíciles de predecir y de calcular. El cuerpo está ahí, la carne ocupa un volumen, se afirma una presencia en la calle, en una especie de solar baldío o callejón en el que crece la hierba que da título a la acción. La imagen muestra un espacio sin duda específico, un lugar apartado, en cierto sentido marginal, que parece estar fuera del recorrido habitual del ciudadano normativo. La presencia en él de una mujer podría resultar perturbadora, pues desafía las leyes del buen comportamiento femenino.

Leída en este sentido, la imagen que documenta la desaparición da cuenta de la problemática inherente a ese estar precario, y la silueta se convierte en evidencia y trazo de una prohibición simbólica. El tránsito de esta mujer, la presencia de este cuerpo, se ven bruscamente interrumpidos por un suceso que se oculta: el dibujo queda como evidencia de la transgresión de las normas del buen comportamiento femenino, y la desaparición es su consecuencia.

Al explorar la visibilidad/invisibilidad del cuerpo femenino, se apela a las condiciones sociales y políticas del momento, y al papel asignado a las mujeres en el interior de la arena pública. La fecha en la que Olga L. Pijoan realiza 
la acción, 1973, previa a la muerte del dictador, y los inicios de los años setenta en general, están marcados por una mayor visibilidad y un mayor acceso de las mujeres a aquellos espacios que tradicionalmente les habían sido vedados. La acción revela una voluntad de tomar esos espacios, de reafirmar la presencia del cuerpo silenciado y de su subjetividad.

Conviene tener en cuenta que la visibilidad de las mujeres en aquel momento se juega en diversos contextos. Por primera vez, un grupo bastante considerable de mujeres accede al ámbito artístico y vanguardista del momento. Es cierto que se trataba de un tipo de prácticas muy experimentales, que en aquel momento no tenían como correlato directo la profesionalización. De hecho, muchas de ellas nunca llegaron a "hacer carrera" como artistas después de esta etapa más experimental, y fueron pocas las que recibieron reconocimiento. $Y$ aunque a pesar de que, mayoritariamente, las artistas afirman no haber sufrido ningún tipo de discriminación por cuestiones de género en el ámbito artístico del momento, en lo que se refiere a sus compañeros de trabajo, a la crítica y a los espacios donde se presentaban sus producciones, está claro que existen formas discriminatorias muy sutiles que a largo plazo dejan sentir sus efectos.

Veo en la acción de Olga L. Pijoan una afirmación de la presencia de mujeres artistas en el ámbito artístico del momento, que se materializa en situar el cuerpo ocupando un espacio, y que supone, al mismo tiempo, una apuesta por la experimentación con nuevos medios en general y por el arte de acción en particular.

En Herba, el cuerpo femenino y las problemáticas a él asociadas se negocian en la dicotomía entre ausencia y presencia.

En algunas propuestas de la artista cubana Ana Mendieta y en varias fotografías de la estadounidense Francesca Woodman aparecen huellas, marcas o siluetas en sustitución del cuerpo físico de la artista. Al igual que en Herba, en estas intervenciones puede identificarse algo relacionado con una especie de precariedad inherente a la presencia como sujeto del cuerpo femenino, como si ésta nunca estuviese garantizada, como si hubiera una tensión constante entre la voluntad de aparecer y el deseo de esconderse de alguien o algo: de desaparecer. En la huella, en la ausencia, se evidencian las implicaciones de la presencia.

Amelia Jones analiza la serie Siluetas (1973-1980) de Ana Mendieta, especialmente la forma en la que el cuerpo se ausenta paulatinamente. Seńala que si bien los trabajos de Mendieta han sido conceptualizados mayormente como rituales corporales con ideas espirituales concernientes a la madre tierra, existen en ellos otros aspectos, que, en palabras de la autora, "rompen profundamente 
con el deseo moderno de presencia y transparencia de significados". ${ }^{5}$ Jones alude a la forma en que el cuerpo se presenta: en ese juego de ausencia/presencia, en la aparición/desaparición, se produce algo más que una relación con rituales ancestrales o con un componente fantasmático. La forma en que se presentan estos cuerpos difiere del modelo hegemónico de presentación corporal, en el que el cuerpo aparece como un ente completo y sin fisuras, seguro y confortable en su puesta en escena. Los cuerpos ausentes, por el contrario, son cuerpos incompletos, fragmentados, fragmentables y, sobre todo, cambiantes y abiertos a la transformación. Son cuerpos atravesados por la historia, por el género, por la raza, por la clase social. Cuerpos para ser reescritos.

De algún modo, los cuerpos del performance, de la acción, restituyen ese cuerpo carnal que da cuenta de que todo sujeto, toda subjetividad, es frágil y permanece siempre amenazada. El cuerpo como lugar al que uno/a está condenado remite a la vulnerabilidad inherente a todo cuerpo en su estatuto carnal, pero también al cuerpo como lugar en el que se vierte la ideología, la construcción de subjetividades, a veces utópicas, por medio de dar forma a esa carne mediante el mandato y la asunción de normativas que domestican al cuerpo y lo convierten en algo dócil.

Estos cuerpos que aparecen, que se presentan de otras formas, desafían la concepción del cuerpo utópico, despojado de carne, y con ello un modelo de sujeto, el que Amelia Jones identifica como sujeto moderno. Conceptualizar el cuerpo como el lugar en el que se juega la fragmentación de la identidad monolítica es un rasgo común que comparten muchas de las acciones corporales realizadas en las décadas de los años sesenta y setenta, y adquiere especial relevancia en las propuestas de muchas mujeres artistas.

\section{Hacer y deshacer el género}

Por medio de la pose, el maquillaje y el disfraz, el artista Carlos Pazos pone en escena un cuerpo que se desmarca de los modelos de masculinidad considerados "aptos" en la época. Sus acciones mezclan la experiencia vital y la artística a partir de la construcción de personajes o alter egos que contestan tanto a la representación tradicional de la masculinidad como a la estética progre (definida

I5. Amelia Jones, Body Art: Performing the Subject (Mineápolis: University of Minnesota Press, 1998), 26 (la traducción es mía). 
por Pazos como "de barba, chiruca y jersey de cuello alto", en definitiva, "poco elegante y repetitiva”) ${ }^{16}$ y barbuda típica del activista de los años setenta. Sus apariciones en el ámbito artístico barcelonés, al igual que sus fotoperformances, constituyen elaboradas puestas en escena de una identidad que se aparta de las representaciones socialmente aceptadas en aquel momento y da cuenta de que la masculinidad también se materializa por medio de la reiteración de actos.

En la serie Voy a hacer de mi una estrella (1975), Pazos construye un personaje por medio de la imitación de las poses y los atuendos de algunas estrellas de cine, como Rodolfo Valentino, Marlon Brando, Clark Gable o Humphrey Bogart (figs. 2 y 3). Mediante la reiteración, el artista pone en jaque la existencia de un original, en este caso, de una identidad esencial y constitutiva, y demuestra que la repetición performativa de actos corporales puede producir nuevos cuerpos y nuevas adscripciones identitarias. Las fotografías congelan la imagen de un cuerpo dúctil y maleable, que escapa a las definiciones estancas de una masculinidad que, a diferencia de la feminidad, tardaría todavía años en ser cuestionada por las prácticas artísticas y por la teoría. En este sentido, el trabajo de Pazos puede considerarse pionero en el contexto español, cercano y contemporáneo a propuestas como la del artista suizo Urs Lüthi, y próximo también a trabajos como los de Hannah Wilke (SOS Starification Object Series, 1974), Dorothèe Selz (Mimètisme Relatif, 1973), Manon, o, algo más tardíamente, los Film Stills (1977-1980) de Cindy Sherman, en los que la artista imita las poses de la feminidad del cine clásico estadounidense, develando su constitución performática e ideológicamente determinada.

Es necesario tener en cuenta que en el trabajo de Pazos la acción no acaba cuando se toma la fotografía, sino que trasciende el estatismo de la imagen que queda como resto de la misma: "No son sólo las fotos. La fotografía es simplemente un fotograma de la performance diaria, de lo que a mí me gustaba poner en la calle. Pero yo salía así a la calle, cada día." ${ }^{\text {I7 }}$

Los personajes que materializa se nutren del dandismo, de la estética andrógina de un David Bowie al que Pazos vio actuar en Londres, del rock-and-roll, y de una manera de entender la "aparición" que está estrechamente relacionada con todo aquello que en el contexto de la España inmediatamente posfranquista pudiera leerse como provocación. Los personajes de Pazos, indistinguibles del propio Pazos, rompen el estrecho marco del arte e irrumpen en las calles de

I6. Entrevista a Carlos Pazos, realizada por la autora, Barcelona, 2012.

I7. Entrevista a Carlos Pazos, realizada por la autora, Barcelona, 2012. 
2. Carlos Pazos, Voy a hacer de mi una estrella, 1975 , $6 \mathrm{I} \times 40 \mathrm{~cm}$. Barcelona. Serie de 2I fotografías en blanco y negro con impresión tipográfica y tiraje a la gelatina de plata. Colección MACBA. Fundació Museu d'Art Contemporani de Barcelona. (C) Carlos Pazos. Reproducción autorizada por el artista.

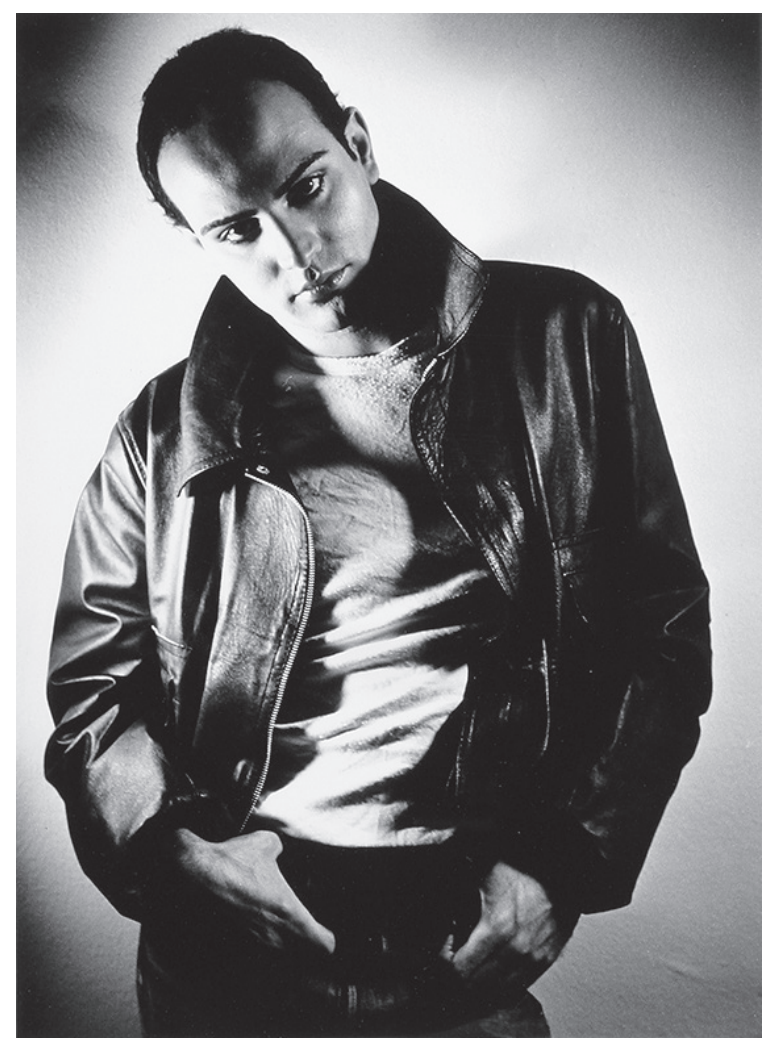

la Barcelona de los años setenta. El artista, el personaje y su trabajo se confunden y se pierden en una amalgama de gestos, apariciones y repeticiones.

Esto provoca que el performance sea tan original como la copia sobre la que se instituye. Al no existir una esencia que funja como referente, el acto, el gesto, el disfraz devienen en máscaras de la nada. Y el cuerpo, el lugar sobre el que se juega una identidad que ha dejado de ser monolítica y estrictamente definible, se convierte en algo flexible y maleable. La mitificación de la estrella a su vez trae consigo la del artista cargada de ironía. El narcisismo que exhuman las fotografías, en las que Pazos juega a convertirse en el objeto de la mirada del otro, pone sobre la mesa cuestiones relacionadas con la construcción del deseo a partir de mirar y ser mirado, y también conduce a repensar el estatuto 


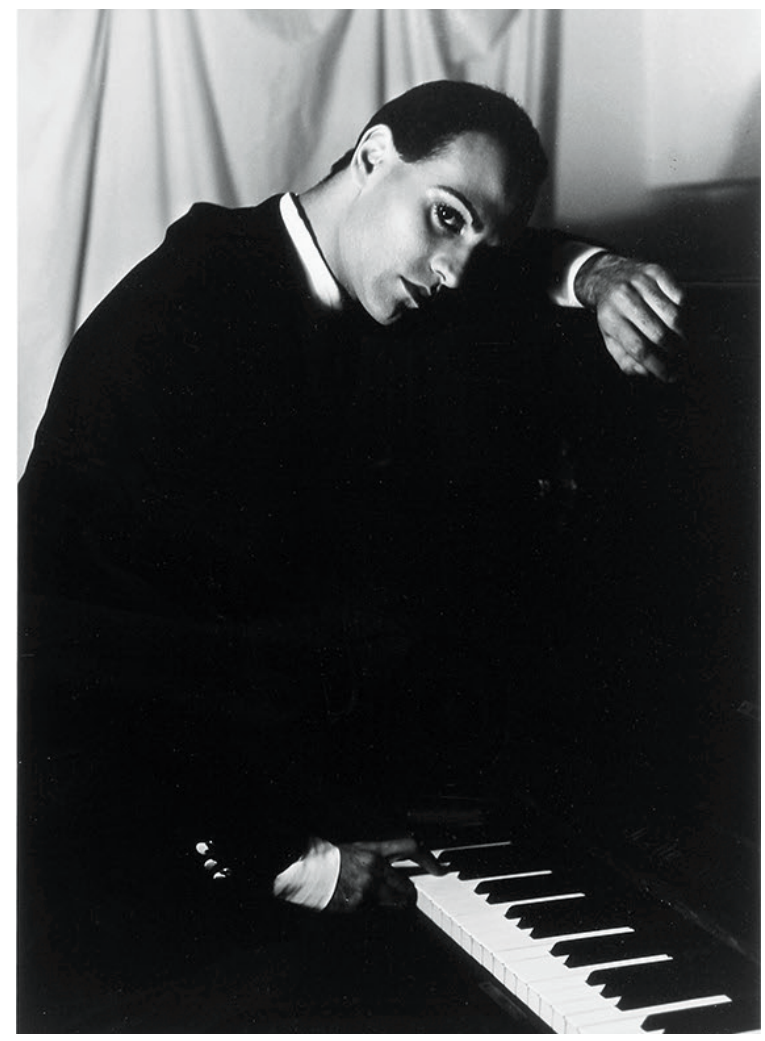

3. Carlos Pazos, Voy a hacer de mi una estrella, 1975 , $6 \mathrm{I} \times 40 \mathrm{~cm}$. Barcelona. Serie de 2I fotografías en blanco y negro con impresión tipográfica y tiraje a la gelatina de plata. Colección масва. Fundació Museu d'Art Contemporani de Barcelona. (C) Carlos Pazos. Reproducción autorizada por el artista.

de un cuerpo, masculino en este caso, que se ofrece a la mirada y a ser modelado por medio de su presentación-representación.

La identificación del artista con la "estrella" permite repensar el papel del primero en un contexto en el que las prácticas con nuevos medios están posibilitando otros modos de entender la producción. Pazos, el artista, se diluye en las imágenes que construye. Como las estrellas de cine que imita, que "dejan de ser" para convertirse en representaciones del glamour por medio de la puesta en marcha del artificio, en simples estereotipos.

Es pertinente analizar el tipo de imagen de la masculinidad que pone en escena Carlos Pazos. Hay en ella un intento de disidir de una estética masculina que nace en la época como contestataria respecto a los modelos impuestos por el régimen, pero que termina por convertirse en norma en el interior de determinados circuitos juveniles politizados y/o intelectualizados: la estética progre. 
La producción de Voy a hacer de mi una estrella coincide con la agonía del dictador: el artista recuerda que varias de las fotografías que componen la serie se tomaron el mismo día de la muerte de Franco, el 20 de noviembre de 1975. Es interesante pensar cuáles eran los modelos de masculinidad promovidos por los aparatos representacionales de la época. La publicidad y el cine ofrecen campos de análisis privilegiados, pues además de materializar y corporeizar estos modelos, se erigen en transmisores de los mismos. El cine de la época, concretamente el cine del destape, populariza un tipo de masculinidad que nada tiene que ver con los modelos hollywoodenses de los que Pazos se apropia. Frente al atractivo físico, la elegancia y la caballerosidad de actores como Clark Gable o Rodolfo Valentino, en España triunfó (al menos en las taquillas) un estereotipo masculino más bien poco agraciado físicamente, tosco y machista, representado por actores como Fernando Esteso o Alfredo Landa, por citar algunos.

El colectivo valenciano ORGIA ${ }^{\mathrm{I} 8}$ ha analizado en algunos de sus trabajos la masculinidad prototípica del cine español durante las décadas de los sesenta y los setenta. La definen como "estética Manolo", plagada de estereotipos "cañís, antichic y casposos" y le otorgan las siguientes características: "voracidad sexual, competitividad, chulería y violencia, tosquedad e incultura, derroche, ludopatía y demostración ostentosa del poder económico y afición por bares y whiskerías". 19

Las imágenes de estrellas de cine que Pazos performa son diametralmente opuestas a este modelo y, además de la elegancia y el glamour que las caracteriza, poseen un componente de ambigüedad sexual que desafía al modelo de macho ibérico preponderante en las representaciones de la época. En Voy a hacer de mi una estrella, las masculinidades que aparecen codificadas son diversas y variadas. Subyace a todas ellas la evidencia de lo mimético: además de que la mayoría de las imágenes son fácilmente identificables con las fotografías originales de los actores, es claro el recurso al artificio de quien posa. La repetición del maquillaje, el atuendo y los gestos remiten, en última instancia, a un tipo de masculinidad afeminada.

Los fotoperformances de Pazos subrayan que la importancia de las imágenes y del cine, cuyo alcance durante las décadas de los sesenta y los setenta fue masivo, como constructores de estereotipos y normas de género, no debe subes-

I8. Organización Reversible de Géneros Intermedios y Artísticos, colectivo conformado actualmente por Sabela Dopazo, Beatriz Higón, Carmen Muriana y Tatiana Sentamans.

19. ORGIA, "Bastos, copas, oros, espadas y dildos. Los reyes de la baraja española", en Fugas subversivas: reflexiones híbridas sobre la identidad (Universitát de Valencia, 2005), 95. 
timarse. Muchos de los modelos de feminidad y masculinidad preponderantes en la época eran encarnados por hombres y mujeres que tenían como referentes a las estrellas de cine.

Durante aquellos años, Carlos Pazos fue objeto de todo tipo de burlas e insultos en sus paseos barceloneses: marica y puta eran los más comunes. Las reacciones que su presencia suscitaba variaban dependiendo de la zona de la ciudad: en la parte alta, feudo de la burguesía, predominaban las miradas de desprecio y alguna que otra interpelación a su presunta homosexualidad; ramblas abajo, en los alrededores de ese Barrio Chino que tan bien retrató Jean Genet ${ }^{20}$ las cosas llegaron a complicarse en más de una ocasión. Sin embargo, no hay constancia de que Carlos Pazos tuviera problemas con la policía o de que fuese detenido debido a la "ambigüedad sexual" de la que hacía gala.

Peor suerte corrió José Pérez Ocaña, pintor, anarquista y performer callejero andaluz que vivió en la Barcelona "aperturista" de los ańos setenta. El 24 de julio de 1978 Ocaña fue apaleado y detenido por las fuerzas del orden mientras paseaba por las Ramblas vestido de "vieja jorobá", uno de sus atuendos habituales. ${ }^{21} \mathrm{Al}$ parecer, había asistido junto a algunos compañeros a la verbena de la Plaza de San Miguel, y en el momento de su detención se encontraba en las inmediaciones del Café de la Ópera, junto con sus amigos Nazario y José, que también fueron golpeados, detenidos y posteriormente trasladados a la prisión de la Modelo. ${ }^{22}$

Esta detención, como tantas otras mucho menos célebres, demuestra que a pesar de que el franquismo había llegado a su fin, el sistema punitivo seguía aplicándose para sancionar las disidencias corporales, y, como había ocurrido durante el régimen, el castigo se materializaba sobre esos cuerpos indóciles que transgredían los límites de la norma. La Ley de Vagos y Maleantes incluyó en 1954, sin mencionarlos directamente, a homosexuales, travestis y transexuales, en definitiva, a todo aquel que amenazara con su comportamiento, su deseo, o su presencia pública el sistema binario sexo-género. Esta ley fue reemplazada en 1970 por la Ley de Peligrosidad y Rehabilitación Social,

20. Genet vivió en Barcelona a principios de los años treinta. Algunas de sus vivencias pueden encontrarse en su libro Journal du voleur (París: Gallimard, 1949).

2I. Su amigo, el dibujante Nazario, ha seńalado que le gustaba mucho vestirse de vieja, con mońo y el pelo empolvado de blanco, en el documental: Juan J. Moreno, Ocaña, la memoria del sol (España: L.D.Flynn P.C, 2009), 99 min.

22. Véase la hemeroteca del Archivo Ocañí: http://larosadelvietnam.blogspot.mx/2008/o6/ detienen-ocaa.html (consultado el 26 de noviembre de 20I5). 
que los/as perseguirá hasta mediados de los años ochenta, la mayoría de las veces por delitos tipificados como "escándalo público". La ley contemplaba penas de prisión y prohibición de vivir en su localidad durante al menos dos ańos. ${ }^{23}$ La promulgación de esta ley es relevante porque se nombran, por primera vez en el léxico de la dictadura, la homosexualidad, la prostitución, la pornografía o el "gamberrismo". Para Beatriz Preciado, el choque que se da en aquel momento entre dos formas de producir el cuerpo y la subjetividad que históricamente parecían corresponder a periodos distintos, queda develado en la capacidad de esta ley de nombrar y marcar con precisión las formas de peligrosidad social que no pueden ser territorializadas en los patrones de la izquierda tradicional que el régimen tenía ya codificados, lo que provoca que los dispositivos de vigilancia y castigo comiencen a mutar precisamente durante el tardofranquismo, para hacer frente a nuevos sujetos políticos y a nuevas luchas. ${ }^{24}$

Barcelona se consideró durante el franquismo la ciudad más liberal del país, lo cual provocó que muchas personas que no se adaptaban a las normas de género, provenientes de distintos puntos del ámbito estatal, como el propio Ocaña, se trasladaran a ella. Héctor Sanz Castaño comenta que la ciudad "era escenario de prácticas de travestismo y espectacularización del cuerpo transgénero. Prácticas que estaban permitidas exclusivamente dentro del espectáculo, y que fuera de él eran reprimidas con dureza” y señala que Ocaña "interfiere en las categorías masculino/femenino en un espacio público y no dentro de las convenciones del espectáculo". ${ }^{25}$

Las apariciones de Ocaña van más allá que las de Pazos, pues llegan incluso a reprimirse con la intervención de la autoridad. El motivo parece claro: Pazos pone en escena un modelo de masculinidad con rasgos afeminados, pero que sigue siendo fácilmente identificable como masculino, y aunque en cierto modo su presencia erosiona las categorías establecidas, sigue adecuán-

23. Víctor Bedoya, "El franquismo contra las transexuales: expedientes policiales y judiciales", en Mujeres bajo sospecha. Memoria y sexualidad I930-I980, ed. Raquel Osborne (Madrid: Fundamentos, 2012), I65-173.

24. Beatriz Preciado, "La Ocańa que merecemos: campceptualismo, subalternidad y políticas performativas", en Ocaña, 1973-I983: acciones, actuaciones, activismo (Barcelona: Virreina Centre de la Imatge/Centro Cultural Montehermoso, 20I2), 72-I69.

25. Héctor Sanz Castaño, "Imagen artística e identidad masculina en España, del franquismo tardío a la era del sida”, tesis doctoral (Madrid: Universidad Autónoma de MadridFacultad de Filosofía y Letras-Departamento de Historia y Teoría del Arte, 20IO), I33. 
dose a una de ellas. Sin embargo, Ocańa, vestido de mujer, normalmente con atuendos estrafalarios y en diversas ocasiones levantando sus faldas en la calle para mostrar sus genitales masculinos, atenta frontalmente contra la división masculino/femenino hasta desdibujarla.

Ocaña es uno de los ejemplos más claros en la época de un cuerpo que aparece, que irrumpe en el espacio público, y que con su aparición hace y deshace las normas de género. En uno de sus paseos por las Ramblas de Barcelona, ${ }^{26}$ Ocańa lleva un vestido de flores, una pamela con plumas, gafas de sol y su inseparable abanico, que va agitando escoltado del brazo por sus amigos Nazario y Camilo. La ropa, el atuendo, opera como marcador de unas normas de género que Ocaña desafía en varios momentos del paseo cuando levanta sus faldas y deja al descubierto sus genitales masculinos, desconcertando a los viandantes. Las Ramblas están abarrotadas de gente que observa entre atónita y divertida al peculiar cortejo, y que en algunos momentos los sigue para unirse a ellos. Es de suponer que el "espectáculo" se torna abyecto cada vez que los genitales son mostrados; que de alguna manera el propio espectáculo termina abruptamente para adquirir un fuerte componente de "realidad". La representación finaliza en el momento en el que sus genitales salen a la luz, y lo real (entendido en el sentido lacaniano del término, como aquello que no se puede decir, representar o simbolizar) provoca una ruptura y da entrada a algo nuevo, no codificado, y que genera una disrupción que trasciende por completo el concepto de representación o actuación, y se encarna en un cuerpo que no puede ser dicho. El acto de Ocaña provoca que quienes contemplan deban situarse en un lugar indefinido, entre las normas del espectáculo y las de la vida cotidiana, en un intersticio donde el juicio estético se torna moral. En este sentido, la acción de Ocaña es constitutiva de una realidad y, por tanto, autorreferencial. Como apuntó Derrida, ${ }^{27}$ lo performativo no tiene su referente fuera de sí, no describe o representa algo que existe, sino que produce o transforma una situación: opera. Las apariciones de Ocańa producen aquello que realizan, y a partir de poner el acento en la propia operación, introducen dentro de sí la posibilidad de que surja la diferencia. Si la signicidad es en cierto modo eliminada y los referentes difíciles de definir, los actos que produce la corporalidad de Ocaña son

26. Las imágenes pueden verse en el documental de Ventura Pons, Ocaña, retrato intermitente (España: Prozesa Teide P.C., 1978), 85 min.

27. Jacques Derrida, Márgenes de la filosofía, trad. Carmen González Marín (Madrid: Cátedra, I998), I77. 
susceptibles de generar nuevos sentidos y significados, y con ellos la posibilidad de nuevos cuerpos. La ruptura que se produce en el campo de visión cuando unos genitales masculinos se muestran en un cuerpo mirado hasta el momento como femenino, introduce un desvío, una torsión en la práctica citacional que estaba conformando ese cuerpo femenino (haciendo el género) performativamente. La aparición de los genitales fuerza la irrupción de la diferencia, de lo "impuro", que como desvío de la citacionalidad general, da entrada a lo incalculable. Los efectos que la presencia pública de un cuerpo como el que "hace" Ocaña, en ese contexto, en ese momento, resultan, todavía desde una perspectiva actual, difíciles de predecir y de analizar. En ocasiones suscitó el divertimento, en otras la burla, y a veces, también, derivó en la intervención brutal del Estado, que identificó en esa presencia una amenaza para el mantenimiento del statu quo y decidió intervenir y legislar sobre ese cuerpo y sobre los espacios sociales que podía estar configurando.

Las maneras en las que podemos o no aparecer en el espacio público están estrechamente relacionadas con las normas de género. Y la precariedad, como recuerda Judith Butler, tiene mucho que ver con esas mismas normas, pues "sabemos que quienes no viven sus géneros de una manera inteligible entran en un alto riesgo de acoso y violencia". ${ }^{28}$

Las prácticas de Ocaña fueron eminentemente contraculturales, como muestra su exclusión de la elite artística de la época, y se definían principalmente por la reapropiación del espacio público que perpetraba su cuerpo, atravesado por una triple exclusión: inmigrante andaluz, de clase baja y, además de homosexual, performando un género no codificado y, por tanto, difícil de identificar con los modelos existentes.

\section{Contragestos}

El gesto contradice al silencio: es la estrategia que usan quienes no pueden hablar para tomar la palabra. Es también la forma en la que aquello que no se puede decir ni nombrar, de pronto es dicho.

El espacio público de una dictadura es siempre un espacio de censura, un espacio de constricción y de sometimiento de los cuerpos que lo transitan y lo

28. Judith Butler, "Performatividad, precariedad y políticas sexuales", conferencia impartida en la Universidad Complutense de Madrid el 8 de junio de 2009. 
ocupan. Los trabajos analizados hasta el momento perpetran rupturas y apropiaciones de ese espacio, desvelan cómo operan y desde dónde parten las distintas estrategias que pueden desplegarse para construir un performance en espacios marcados por la censura.

En torno a 1966 Gonçal Sobrer realizó una acción en el barrio del Poble Nou de Barcelona. Dos fotografías de la misma aparecen recogidas en una publicación ${ }^{29}$ editada con motivo de una exposición del artista, y la investigadora Pilar Parcerisas también da cuenta de ella. ${ }^{30}$ Titulada Dansa de l'afusellament (Danza del fusilamiento), en ella, Sobrer simula mediante gestos corporales un fusilamiento (fig. 4). En la primera instantánea, vemos al artista vestido de traje, apoyado en la pared y maniatado, a punto de recibir el disparo. En la segunda, el cuerpo se retuerce y reacciona al impacto de la bala.

El gesto callejero de Sobrer, en la Barcelona de I966, posee unas implicaciones que no pueden pasarse por alto. Por medio de él, el artista cita una imagen socialmente omnipresente, pero que a la vez no puede ser citada, pues su representación no está autorizada. La acción extrae el fusilamiento de su contexto habitual y lo coloca en un lugar ambiguo, a medio camino entre lo escénico y la realidad.

Gonçal Sobrer cita los cientos de fusilamientos que tuvieron lugar en el Camp de la Bota, un suburbio de las afueras de Barcelona que ocupaba una parte del actual barrio de Poble Nou. En el Camp de la Bota, donde había un castillo militar que tras la victoria de los nacionales se convirtió en cárcel, se fusiló entre 1939 y 1952 a I,704 personas. ${ }^{31}$ Aunque la etapa más cruenta fue al final de la guerra civil y durante los primeros años de la posguerra, no había pasado tanto tiempo desde que tuvieron lugar los últimos fusilamientos en este emplazamiento.

El gesto de Sobrer se presenta como un antídoto contra la desmemoria que acechaba los años de la bonanza económica propia de los últimos tiempos de la dictadura. Pero la Dansa de l'afusellament no puede verse únicamente como una apelación a la memoria histórica, pues la represión era todavía una realidad,

29. Gonçal Sobrer, Òpera neo xava (Barcelona: Galería Syra, 1966).

30. Pilar Parcerisas, Conceptualismo(s). Poéticos, politicos y periféricos. En torno al arte conceptual en España, 1964-1980 (Madrid: Akal, 2007), I07.

3I. Para mayor información, véase el proyecto archivístico del artista Francesc Abad: http:// www.francescabad.com/campdelabota/ (consultado el 26 de noviembre de 20I5). 

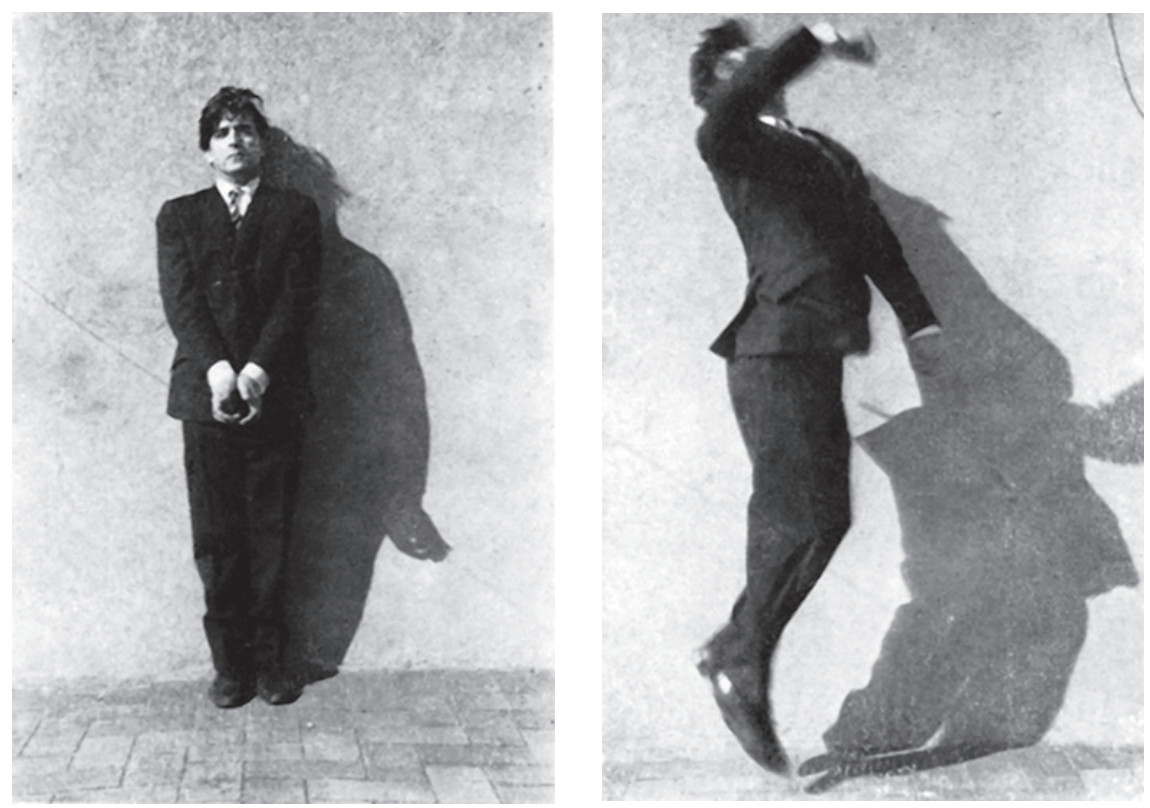

4. Gonçal Sobrer, Dansa de l'afusellament, 1966. Barcelona. Cortesía del artista.

y los fusilamientos, aunque habían dejado de estar a la orden del día, representaban una amenaza palpable, como se constataría algunos años después. ${ }^{32}$

Mediante la acción, el artista fija la violencia del régimen franquista en el espacio público, la reconoce; la cita y la repite para evitar que la historia reciente de un lugar concreto (el Poble Nou) se borre y caiga en el olvido.

En este sentido, la Dansa de l'afusellament subraya que toda acción performática siempre posee resonancias locales y contextuales. El gesto corporal de Sobrer perturba la cotidianeidad de la dictadura a la vez que apela a la historia más reciente del barrio. Es una forma de ruptura del silencio, un no hablar a la vez que se habla. Porque cuando el lenguaje deviene acto y se materializa a través del cuerpo, normalmente dice más de lo que pretende decir. En el interior de un contexto dictatorial, en el que existe un exhaustivo control sobre los discursos, los espacios y los ciudadanos, ciertos aspectos del cuerpo son susceptibles de escapar a este control.

32. El 27 de septiembre de 1975 el régimen franquista fusiló a Juan Paredes Manot (Txiki), Ángel Otaegi, Humberto Baena, José Luis Sánchez Bravo y Ramón García Sanz. 
La Dansa de l'afusellament se inserta en un espacio y un momento concretos, en los que habían sucedido y estaban sucediendo una serie de acontecimientos que determinaron forzosamente las implicaciones que tiene la puesta en escena de esta acción. La historia del Poble Nou queda irremediablemente fijada a ella y al cuerpo de Sobrer como significante capaz de acoger en sí múltiples significados.

Sin duda 1966 fue un año representativo para la resistencia antifranquista en Barcelona. Durante el mes de marzo, el Sindicato Democrático de Estudiantes de la Universidad de Barcelona, que era una organización clandestina, convocó a una asamblea en el convento de la orden de los Capuchinos en el barrio de Sarriá. El edificio fue inmediatamente sitiado por las fuerzas de seguridad, lo que derivó en un encierro de resistencia que duró más de 72 horas, hasta que la policía irrumpió en el recinto. Conocido como La Capuchinada, el suceso tuvo un fuerte eco en la sociedad del momento. Los partidarios del régimen se indignaron por el apoyo brindado por la Iglesia a los disidentes, la izquierda lo celebró como un paso más en la lucha contra el franquismo y la presencia policial en la ciudad aumentó considerablemente.

Recordar La Capuchinada sirve para contextualizar la acción callejera de Sobrer, para insertarla en un espacio compartido con otras voces disidentes también acostumbradas a transitar por los bordes del silencio, y a utilizarlo como referente desde el cual proponer estrategias para decir aquello que no se podía decir. El gesto de reunirse o de encerrarse son comparables al de aparecer sin hablar, al gesto que deja al cuerpo hablar sin voz.

Lo que la acción de Sobrer convoca es algo que ya está ahí, él simplemente lo encarna, y de este modo la represión se materializa en su cuerpo, un cuerpo que cita a todos aquellos cuerpos fusilados que lo precedieron, pero también a los que lo sucederán. El acto y el gesto fijan el cuerpo a una pared del Poble Nou, y a su vez quedan fijados en las fotografías que documentan la acción. La cita al fusilamiento adquiere hoy nuevas connotaciones derivadas de los debates sobre la memoria histórica acaecidos en España durante los últimos años. En este sentido, el gesto de Sobrer vuelve a citarse, y plantea una pregunta sobre sus implicaciones en el contexto y en la coyuntura actuales: ¿qué implica hacer aparecer estas acciones, estos cuerpos, en el momento de la España de hoy? Recuperarlas por medio de fragmentos, de metonimias, de testimonios, hace aparecer aquello que desde el momento en que apareció, por su propia constitución, ya estaba destinado a desaparecer. No puede negarse que su aparición convoca toda 
una serie de cuestiones políticas y aboga por el reconocimiento de todo aquello que el franquismo y la transición continuista silenciaron e hicieron desaparecer.

Las acciones analizadas comparten una voluntad de abordar las posibilidades de juego y resistencia que se esconden en el interior de un espacio fuertemente controlado. La alteración de los usos normativos del cuerpo es capaz de instaurar tipos de presencia diferentes, de dar cuenta de nuevas experiencias y de inaugurar espacios liminares de posibilidad.

Es el campo de lo artístico el que permite fundar visualidades periféricas. Inventar estrategias que sirvan para proponer nuevas imágenes, nuevas presencias, nuevas re-presentaciones. Estrategias que hacen posible fundar nuevos lugares desde los que se pueda proponer lo imposible en otros. Estrategias estéticas que posibilitan ir más allá de la evidencia y del aparato representacional dominante. Porque como bien señala Ludmer, la estrategia, o la treta (típica táctica del débil), "consiste en que, desde el lugar asignado y aceptado, se cambia no sólo el sentido de ese lugar, sino el sentido mismo de lo que se instaura en él." 33 \&

33. Ludmer, "Tretas del débil", 5 . 